\title{
Type 2 diabetes mellitus is associated with obesity, smoking and low socioeconomic status in large and representative samples of rural, urban, and suburban adult Greek populations
}

\author{
Nicholas Tentolouris, ${ }^{1}$ Alexandros Andrianakos, ${ }^{2}$ Georgios Karanikolas, ${ }^{2}$ \\ Dimitrios Karamitsos, ${ }^{2}$ Panagiotis Trontzas, ${ }^{2}$ Petros Krachtis, ${ }^{2}$ Fotis Christoyannis, ${ }^{2}$ \\ Elpiniki Tavaniotou, ${ }^{2}$ Zouboulio Nikolia, ${ }^{2}$ Evaggelia Kaskani, ${ }^{2}$ Leonidas Kontelis, ${ }^{2}$ \\ Petros P. Sfikakis ${ }^{1}$ \\ ${ }^{1} 1^{\text {st }}$ Department of Propaedeutic Medicine, Athens University Medical School, ${ }^{2}$ Rheumatic Disease Epidemiology \\ Section, Hellenic Foundation for Rheumatological Research, Athens, Greece
}

\begin{abstract}
OBJECTIVE: In this cross-sectional epidemiologic study we examined the association between type 2 diabetes mellitus and demographic, clinical, and socioeconomic parameters in large rural, urban and suburban populations of adult Greeks. DESIGN: Of the total target adult population ( $\geq 19$ years, $n=14233$ ) in nine selected geographical regions covering rural, suburban, and urban areas of Greece, 10,647 subjects were included in the study. Data were collected by physicians who interviewed subjects at their homes between 1996 and 1999. RESULTS: A total of 8740 subjects participated (response rate 82.1\%). Among participants there were 360 subjects with type 2 diabetes. Multivariate logistic regression analysis after adjustment for factors associated with type $2 \mathrm{DM}$ in univariate analyses including occupation, education level, place of residence, and number of persons living together demonstrated that advancing age, obesity - but not overweight status - and smoking in the past were associated with higher odds of type 2 diabetes. Moreover, low socioeconomic status was associated with type 2 diabetes independently of the effects of age, obesity, and smoking. CONCLUSIONS: In large representative rural, urban, and suburban populations of adult Greeks, type 2 Diabetes was associated with advancing age, obesity, exposure to smoke, and low socioeconomic status.
\end{abstract}

Key words: Type Greece, Obesity, Risk Factors, Socioeconomic Status, 2 Diabetes Mellitus

Address for correspondence:

Nicholas Tentolouris, MD, 33 Lakonias Street, 11523 Athens, Greece, Tel.: +30 210745 6261, Fax: +30 210779 1839, e-mail: ntentol@med.uoa.gr

Received 28-01-12, Revised 09-05-12, Accepted 13-07-12

\section{INTRODUCTION}

Type 2 diabetes mellitus (DM) is the most common chronic metabolic disease, affecting about $6 \%$ of the adult population in the western world, ${ }^{1}$ with a 
considerable proportion of the population remaining undiagnosed, while incidence is also rising at an alarming pace in the non-western world. ${ }^{2}$ Among chronic diseases, type $2 \mathrm{DM}$ is moreover one of the most costly and onerous, being a major cause of cardiovascular disease, blindness, renal failure, and amputations ${ }^{3,4}$ with increasing prevalence worldwide. ${ }^{1,4}$ Additionally, prevalence of overweight and obesity, prime risk factors for type $2 \mathrm{DM}$, is increasing. ${ }^{5,6} \mathrm{~A}$ large number of studies have shown that an increase in the prevalence of obesity is followed by a similar rise in the prevalence of type $2 \mathrm{DM}$ and that obesity is responsible for more than $80 \%$ of all cases of type 2 DM. ${ }^{7,8}$ Identification of risk factors associated with and prevention of type $2 \mathrm{DM}$ is therefore a major priority in healthcare planning in many countries. The aim of the present cross-sectional epidemiological study was to examine the association between type $2 \mathrm{DM}$ and demographic, clinical, and socioeconomic parameters in a representative sample of the adult Greek population.

\section{SUBJECTS AND METHODS}

\section{Study population}

This study was run in parallel with the ESORDIG study, a cross-sectional survey which examined the prevalence of rheumatic diseases in Greece. Details on the ESORDIG study design, study population, subject recruitment, and evaluation have been reported previously ${ }^{9-12}$ Briefly, the study was conducted from March 1996 to April 1999 on the total adult population (aged $\geq 19$ years) in two urban, one suburban, and four rural areas located in northern, central, and southern mainland Greece ( 8547 subjects), as well as on 2100 out of 5686 randomly selected adult subjects in one additional rural and one suburban community. In the latter areas, every second and third household from a randomly chosen starting point, respectively, was selected. All adult members of the non-selected and selected households were asked to participate in the study.

The main selection criteria for these areas were the widest possible representation of rural, urban, and suburban mainland Greek populations. The research was conducted exclusively by the participating local physicians, since most of these areas are near their permanent residences. In Greece, an area is considered urban if its population is more than 10,000 inhabitants, suburban if between 2000 and 10,000, and rural if less than 2000 inhabitants.

Based on the 1991 population census ${ }^{13}$ and on the calculated population changes per year based on 1991 and 1981 population census data, it was estimated at the beginning of the study (March 1996) that the total population of the study areas came to 20,051 subjects of whom 14,233 were adults who thus constituted the total target population (Table 1). The study was conducted by experienced local physicians who visited the participating population at their homes. The home visit involved an interview with each participant based on a standardized questionnaire; its purpose was to obtain a variety of information on socio-demographic characteristics (Table 2), a medical history which included a specific questionnaire regarding the presence of DM, the year of diagnosis, and the type of DM. Diagnosis of DM was based on the following criteria: 1) participants had a history of DM diagnosed by the family doctor or the primary care physician, and 2) they were on treatment with antidiabetic tablets, insulin or a combination of the two. ${ }^{14}$ Type $1 \mathrm{DM}$ was diagnosed when the onset of diabetes occurred before the age of 30 years of age in the presence of symptoms of diabetes and/or ketoacidosis and the patients had been treated continuously with insulin in the first two years post-diagnosis. Additionally, type $1 \mathrm{DM}$ was diagnosed when the onset of DM was at older age and the patients had been treated continuously with insulin in the first two years after diagnosis. Type 1 DM, other types of DM, and gestational DM were excluded. Participants were asked to report their own height and weight, which were used to calculate the body mass index (BMI), and they were grouped as normal weight $\left(\mathrm{BMI}<25.0 \mathrm{~kg} / \mathrm{m}^{2}\right)$, overweight (BMI 25.0-29.99 kg/m²), and obese (BMI $>30.0 \mathrm{~kg} /$ $\left.\mathrm{m}^{2}\right)$. Finally, a random sample of non-participants in the full survey (one out of six persons who refused to participate in the study) in two areas (a total of 60 subjects) was telephoned and a home visit was arranged. A short questionnaire on sociodemographic characteristics, medical history, diagnosed DM, and the reasons for non-participation in the study was completed. We reported previously on the prevalence of DM and obesity in this sample. ${ }^{15}$ 
Table 1. Study population and participation rate in urban, suburban, and rural areas

\begin{tabular}{|c|c|c|c|c|c|c|c|c|}
\hline \multirow[b]{3}{*}{ Area } & \multicolumn{8}{|c|}{ Population } \\
\hline & \multirow[b]{2}{*}{ All } & \multirow[b]{2}{*}{ Total } & \multicolumn{3}{|c|}{ Target Adult } & \multicolumn{3}{|c|}{ Participants (Participation Rate, \%) } \\
\hline & & & Final & M & $\mathbf{F}$ & $\mathbf{M}$ & $\mathbf{F}$ & Total \\
\hline \multicolumn{9}{|l|}{ Urban } \\
\hline Kantza & 3695 & 2587 & 2587 & 1252 & 1335 & $1120(89.5)$ & $1191(89.2)$ & $2311(89.3)$ \\
\hline Pikermi & 741 & 482 & 482 & 235 & 247 & $188(80.0)$ & $213(86.2)$ & $401(83.2)$ \\
\hline \multicolumn{9}{|l|}{ Suburban } \\
\hline Panaetolio & 3249 & 2274 & 2274 & 1085 & 1189 & $882(81.3)$ & $885(74.4)$ & $1767(77.7)$ \\
\hline Thermi & 6445 & 4458 & $1486^{*}$ & 732 & 754 & $591(80.7)$ & $614(81.4)$ & $1205(81.1)$ \\
\hline \multicolumn{9}{|l|}{ Rural } \\
\hline Agiasma & 1047 & 781 & 781 & 388 & 393 & $313(80.7)$ & $332(84.5)$ & $645(82.6)$ \\
\hline Drosato & 1119 & 854 & 854 & 465 & 389 & $345(74.2)$ & 337 (86.6) & $682(79.9)$ \\
\hline Nea Pella & 1654 & 1228 & $614 \dagger$ & 295 & 319 & $236(80.0)$ & $265(83.1)$ & $501(81.6)$ \\
\hline Grammatico 1172 & 846 & 846 & 443 & 403 & $318(71.8)$ & $350(86.8)$ & $668(79.0)$ & \\
\hline Evrostini & 929 & 723 & 723 & 360 & 363 & $276(76.7)$ & $284(78.2)$ & $560(77.5)$ \\
\hline Total & $20,05114,233$ & 10,647 & 5255 & 5392 & $4269(81.2)$ & $4471(82.9)$ & $8740(82.1)$ & \\
\hline
\end{tabular}

* Randomly selected adults at a ratio 1:3. $\uparrow$ Randomly selected adults at a ratio 1:2.

Table 2. Questionnaire on sociodemographic characteristics

\begin{tabular}{|c|c|c|c|}
\hline \multicolumn{2}{|l|}{ Factors } & \multicolumn{2}{|l|}{ Definitions } \\
\hline Sex & & \multicolumn{2}{|l|}{ Male/female } \\
\hline Age & & \multicolumn{2}{|l|}{ All ages and age-groups } \\
\hline Residence & & \multicolumn{2}{|l|}{ Urban, suburban, rural } \\
\hline \multirow[t]{3}{*}{ Body mass index } & & \multicolumn{2}{|l|}{ Normal $<25.0 \mathrm{~kg} / \mathrm{m}^{2}$} \\
\hline & & \multicolumn{2}{|l|}{ Overweight: $25.0-29.9 \mathrm{Kg} / \mathrm{m}^{2}$} \\
\hline & & \multicolumn{2}{|l|}{ Obese: $\geq 30 \mathrm{~kg} / \mathrm{m}^{2}$} \\
\hline \multirow{4}{*}{\multicolumn{2}{|c|}{ Alcohol consumption (daily) }} & \multicolumn{2}{|l|}{ None } \\
\hline & & \multicolumn{2}{|l|}{ Modest: up to $0.5 \mathrm{~L}$ of wine or 2 beers } \\
\hline & & \multicolumn{2}{|l|}{ Moderate: $>0.5$ to $1 \mathrm{~L}$ of wine or $3-4$ beers } \\
\hline & & \multicolumn{2}{|l|}{ Heavy: $>1 \mathrm{~L}$ of wine or $>4$ beers } \\
\hline \multirow[t]{2}{*}{ Level of education } & & \multicolumn{2}{|l|}{ Low: $\leq 12$ years of school } \\
\hline & & \multicolumn{2}{|l|}{ High: $>12$ years (college or university) } \\
\hline \multirow{2}{*}{\multicolumn{2}{|c|}{ Occupation }} & \multicolumn{2}{|l|}{$\begin{array}{l}\text { Manual: Unskilled blue-collar workers, such as farmers, fishermen, } \\
\text { herdsmen, skilled manual workers }\end{array}$} \\
\hline & & \multicolumn{2}{|l|}{$\begin{array}{l}\text { Nonmanual: Skilled nonmanual workers, clerks, white-collar } \\
\text { workers, small business owners, artists, university graduates (junior } \\
\text { and senior public/private sector employees, freelance workers), } \\
\text { business people }\end{array}$} \\
\hline \multirow{2}{*}{\multicolumn{2}{|c|}{ Having ever smoked cigarettes }} & \multicolumn{2}{|l|}{ Smoking cigarettes currently and/or in the past } \\
\hline & & Occupation & Level of Education \\
\hline \multirow[t]{2}{*}{ Socioeconomic status } & Low: & $\begin{array}{l}\text { Unskilled blue-collar workers, such as farmers, fisherman, } \\
\text { herdsmen, junior white-collar workers in the private and public } \\
\text { sectors }\end{array}$ & $\leq 12$ years of school \\
\hline & High: & $\begin{array}{l}\text { Professionals in the private/public sector managers, directors, } \\
\text { freelance workers, senior white-collar workers }\end{array}$ & $\begin{array}{l}>12 \text { years } \\
\text { (college or university) }\end{array}$ \\
\hline
\end{tabular}


The study protocol was evaluated and approved by appropriate local and central committees and was conducted under the auspices of the Greek Ministry of Health and the Greek Central Union of Municipalities and Communities of Greece.

\section{Quality control}

Prior to the start of the ESORDIG study, all participating physicians attended a training course that covered the study protocol, how to conduct the interview, and assessment of DM status. Throughout the duration of the study, all the regularly submitted epidemiological forms were centrally controlled and checked for any controversial or missing data. Such observations led to the organization of in-study investigators' meetings and subsequent written guidelines, as required. The effect of the investigator on diagnosing DM and excess body weight as well as the effect of non-selection and random selection of suburban and rural populations on the study results were tested in logistic regression models, in which the dependent variables were DM and excess body weight status and the independent variables were the observer and the selected/non-selected populations.

\section{Statistical analysis}

All data were analyzed by SPSS v. 11.0 for Windows and AnswerTree v. 3.0 for Windows. The values of the parametric data are presented as mean \pm SD. Pearson correlation coefficients were used to compare the age distribution between the study participants, the total target adult population, and the total adult population of Greece based on gender and on urban, suburban, and rural residence. The student $t$-test or one-way analysis of variance (ANOVA) was used to compare mean values, while a $\chi^{2}$ was used to compare categorical variables; $95 \%$ confidence intervals $(\mathrm{CI})$ were given where relevant. A variety of factors shown by $\chi^{2}$ automatic interaction detection to be significantly associated with known diabetes were included in a forward logistic regression model for further analysis. Such factors were age, BMI, residence in urban, suburban or rural areas, level of education, manual or non-manual occupation, smoking habits, number of persons living in a house, and socioeconomic status. Socioeconomic status was defined as low or high based on the level of education and the occupation of the family breadwinner. $P$ values $<0.05$ (two-tailed) were considered statistically significant.

\section{RESULTS}

Of the final target population of 10,647 subjects, 8740 participated in the study (participation rate 82.1\%). Among the participants, 4269 (49\%) were men and $4471(51 \%)$ were women, while $31 \%$ were residents in urban, $34 \%$ in suburban, and $35 \%$ in rural areas; the age range was 19-99 years and the mean age was $47 \pm 17.7$ years. In the age groups $60-69$ and $\geq 70$ years, there were significantly more people in the rural than in the urban and suburban areas $(P<0.001$ for all comparisons). Thus, the mean age of the rural population (49.64 \pm 18.28 years) was significantly different from that of urban $(44.65 \pm 17.03$ years) or suburban dwellers ( $46.30 \pm 17.45$ years) $(P<0.001$ for both comparisons). However, the study population was indeed representative of the general adult population of Greece; using Pearson correlation coefficients we found significant similarities in the age distributions for men and women separately, between the study participants (data collected by the study physicians) and the total target population of the study (data available by the local authorities according to the 1991 and 1981 population census data) $(r=0.85, P<0.001$, and $r=0.84, P<0.001$, respectively), between the study participants and the total adult population of Greece $(r=0.85, P<0.001$ for both genders, and between the total target adult population of the study and the total adult population of Greece according to the 1991 population census ${ }^{9}$ ( $r=0.99, P<0.001$ for both genders). Analogous similarities were found even when the data were analyzed separately for urban, suburban, and rural populations. Logistic regression showed that there was neither a significant inter-examiner or intra-examiner variation in the diagnosis of diabetes and excess body weight nor any effect of non-selection and random selection of suburban and rural populations. Indeed, the inter- and intra-examiner variation in the results was less than $1 \%$. Analysis of data from the random sample of non-responders showed no significant differences from responders with respect to age, sex, and prevalence of DM or body weight status. In addition, the reasons for non-participation were unrelated to DM or the body weight status. 


\section{Associations between type $2 \mathrm{DM}$ and the study parameters}

Of the 8740 participants, 360 [4.11\%, 95\% CI 3.704.52] had type $2 \mathrm{DM}$ (Table 3). Univariate analysis revealed that prevalence of type $2 \mathrm{DM}$ increased significantly with older age $(P<0.001)$, increasing BMI $(P<0.001)$, living in rural regions $(P=0.01)$, low education level $(P<0.001)$, manual occupation $(P=0.01)$, low socioeconomic status $(P<0.001)$, smoking in the past $(P<0.001)$, and fewer subjects living together $(P<0.001)$ (Table 4). Prevalence of known type $2 \mathrm{DM}$ did not differ significantly between males and females. Similarly, there was no difference in the prevalence of type $2 \mathrm{DM}$ among the northern, central, and southern areas of the country or between the selected and non-selected populations.

Multivariate logistic regression analysis in the studied population, after adjustment for region of living (rural, suburban, urban), educational level, occupation, and number of persons living together, demonstrated that the odds of type $2 \mathrm{DM}$ increased significantly with age above 40 years $(P<0.001)$, BMI $\geq 30.0 \mathrm{~kg} / \mathrm{m}^{2}(P<0.001)$, low socioeconomic status ( $P=0.009)$, and smoking in the past $(P=0.001)$, while smoking currently was associated with lower odds of type $2 \mathrm{DM}(P=0.01)$ (Table 5$)$.

\section{DISCUSSION}

Diabetes is a formidable public health issue incur- ring a significant social and economic burden which necessitates a multitude of clinical interventions and public health policy decisions. Population-based studies and identification of risk factors are of particular interest for the development of preventive strategies. However, screening of selected groups of the general population and the non-random, non-populationbased nature of most relevant studies have given rise to wide variations of the reported DM prevalence in Greece in previous studies. ${ }^{16-21}$

The strengths of the present study are: i) a large number of subjects was evaluated in a door-to-door manner by experienced physicians who visited, interviewed, and collected data at their homes; ii) the participants were representative of the total adult target population of the studied areas and, most importantly, of the Greek adult population; iii) a high participation rate was achieved. On the other hand, this study is not without limitations. As in most population-based studies, the determination of DM was based on self-reported, physician-diagnosed DM and was not confirmed diagnostically, although previous data indicated that the reliability of self-reported DM was high..$^{22}$ Additionally, the actual prevalence of the disease, including the non-diagnosed cases, is clearly underreported. Furthermore, data on some established risk factors of type $2 \mathrm{DM}$, such as family history of type $2 \mathrm{DM}$, physical activity, and nutritional factors, are not available.

In our study we found a strong association between

Table 3. Demographic and clinical characteristics of the subjects with known diabetes in the studied population

\begin{tabular}{lcc}
\hline & Type 2 diabetes & Type 1 diabetes \\
\hline $\mathrm{n}$ & 360 & 15 \\
Prevalence $(\%)$ & 4.1 & 0.2 \\
Males/females n (\%) & $164(3.8) / 196(4.4)$ & $6(0.14) / 9(0.2)$ \\
Age (years) & $64.9 \pm 10.9$ & $51.0 \pm 15.8$ \\
Known duration of diabetes (years) & $8.4 \pm 7.42$ & $37.8 \pm 15.9$ \\
Age at diagnosis of diabetes (years) & $56.4 \pm 10.9$ & $13.2 \pm 3.5$ \\
Treatment for diabetes n (\%) & $94(26.1)$ & 0 \\
$\quad$ Diet only & $230(63.9)$ & $0(0)$ \\
$\quad$ Oral antidiabetic medications only & $27(7.5)$ & $15(100)$ \\
Insulin therapy only & & \\
Insulin with oral antidiabetic medications $9(2.5)$ & & \\
\hline
\end{tabular}

Data are mean value \pm SD or $\mathrm{n}(\%)$. 
Table 4. Demographic, clinical and socioeconomic characteristics of the nondiabetic and type 2 diabetic subjects

\begin{tabular}{|c|c|c|c|}
\hline & Nondiabetics* & Known type 2 diabetes* & $P$ \\
\hline $\mathrm{n}$ & 8365 & 360 & \\
\hline \multicolumn{4}{|l|}{ Gender } \\
\hline Men & $4095(49.0)^{*}$ & $164(45.6)$ & \\
\hline Women & $4270(51.0)$ & $196(54.4)$ & $0.20 \dagger$ \\
\hline \multicolumn{4}{|l|}{ Age (years) } \\
\hline $19-39$ & 3318 (39.7) & $6(1.7)$ & \\
\hline $40-59$ & $2875(34.4)$ & $94(26.1)$ & \\
\hline$\geq 60$ & $2172(26.0)$ & $260(72.2)$ & $<0.001 \ddagger$ \\
\hline \multicolumn{4}{|l|}{ Body mass index $\left(\mathrm{kg} / \mathrm{m}^{2}\right)$} \\
\hline$<25.0$ & $4172(49.9)$ & $113(31.4)$ & \\
\hline 25.0-29.99 & 3207 (38.3) & $160(44.4)$ & \\
\hline$\geq 30.0$ & $986(11.8)$ & $87(24.2)$ & $<0.001 \ddagger$ \\
\hline \multicolumn{4}{|l|}{ Region } \\
\hline Rural & $2900(34.7)$ & $151(42.0)$ & \\
\hline Suburban & $2856(34.1)$ & $111(30.8)$ & \\
\hline Urban & $2609(31.2)$ & $98(27.2)$ & $0.01 \ddagger$ \\
\hline \multicolumn{4}{|l|}{ Geographical region } \\
\hline Southern & $3768(45.0)$ & $166(46.1)$ & \\
\hline Central & $1690(20.2)$ & $72(20.0)$ & \\
\hline Northern & $2907(34.8)$ & $122(33.9)$ & $0.91 \dagger$ \\
\hline \multicolumn{4}{|l|}{ Educational level } \\
\hline High & $4180(50.0)$ & $66(18.3)$ & \\
\hline Low & $4185(50.0)$ & $294(81.7)$ & $<0.001 \dagger$ \\
\hline \multicolumn{4}{|l|}{ Occupation } \\
\hline Manual & $2177(26.0)$ & $114(31.7)$ & \\
\hline Non-manual & $6188(74.0)$ & $246(68.3)$ & $0.01 \dagger$ \\
\hline \multicolumn{4}{|l|}{ Socioeconomic status } \\
\hline High & $1517(18.2)$ & $25(6.9)$ & \\
\hline Low & $6837(81.8)$ & $335(93.1)$ & $<0.001 \dagger$ \\
\hline \multicolumn{4}{|l|}{ Smoking status } \\
\hline Non-smokers & $4774(57.1)$ & $227(63.1)$ & \\
\hline Ex-smokers & $676(8.1)$ & $64(17.8)$ & \\
\hline Current smokers & $2915(34.8)$ & $69(19.2)$ & $<0.001 \dagger$ \\
\hline \multicolumn{4}{|l|}{ Alcohol consumption } \\
\hline None & $6562(78.4)$ & $290(80.6)$ & \\
\hline Modest & $1490(17.8)$ & $55(15.3)$ & \\
\hline Moderate & $263(3.1)$ & $11(43.1)$ & \\
\hline Heavy & $50(0.7)$ & $4(1.0)$ & $0.39 \dagger$ \\
\hline \multicolumn{4}{|c|}{ Number of subjects living together } \\
\hline More than two & $6404(76.6)$ & $206(57.2)$ & \\
\hline One or two & $1961(23.4)$ & $154(42.8)$ & $<0.001 \dagger$ \\
\hline \multicolumn{4}{|l|}{ Target population } \\
\hline Selected population & $1638(19.6)$ & $63(17.5)$ & \\
\hline Unselected population & $6727(80.4)$ & $297(82.5)$ & $0.32 \dagger$ \\
\hline
\end{tabular}

* Numbers in parentheses are percentages. †Chi-square test; †one way analysis of variance. 
Table 5. Estimated adjusted effects (odds ratio with $95 \%$ confidence intervals) of risk factors on the prevalence of type 2 diabetes in the studied population by logistic regression analysis

\begin{tabular}{lcc}
\hline & Odds ratio & $\begin{array}{c}\text { 95\% confidence } \\
\text { intervals }\end{array}$ \\
\hline Age group (years) & & \\
$19-39$ & 1.00 (Reference) & \\
$40-59$ & 15.87 & $6.94-36.28$ \\
$\geq 60$ & 50.42 & $22.34-113.78$ \\
Body mass index $\left(\mathrm{kg} / \mathrm{m}^{2}\right)$ & & \\
$<25.0$ & 1.00 (Reference) & \\
$25.0-29.99$ & 1.15 & $0.89-1.48$ \\
$\geq 30.0$ & 1.76 & $1.30-2.37$ \\
Socioeconomic status & & \\
High & 1.00 (Reference) & \\
Low & 1.75 & $1.15-2.67$ \\
Smoking status & & \\
Non-smokers & 1.00 (Reference) & \\
Current smokers & 0.75 & $0.60-0.95$ \\
Ex-smokers & 1.49 & $1.17-1.88$ \\
\hline Additionatvaniables & &
\end{tabular}

Additional variables tested in the model: occupation, education level, region (rural, suburban, urban) and number of subjects living together.

age and prevalence of type $2 \mathrm{DM}$ in both genders. Multivariate analysis demonstrated that the risk of type $2 \mathrm{DM}$ was almost 16 and 50 times higher in the subjects aged 40-59 and $\geq 60$ years, respectively, in comparison with subjects $<40$ years of age. The development of type $2 \mathrm{DM}$ is influenced by attained age and has been demonstrated in previous studies. ${ }^{16-21,23-26}$

With regard to the association between excess body weight and type $2 \mathrm{DM}$, we found that both overweight and obesity were associated with higher prevalence of DM in univariate analysis. However, multivariate analysis demonstrated that only obesity and not overweight status was associated with higher risk of type 2 DM. Data from large studies, albeit confined to the USA, have shown that excess body weight within the classification of 'overweight' is associated with higher risk of type $2 \mathrm{DM}$ and that the association of risk with increasing weight was evident even within the non-obese range. ${ }^{7,24,26}$ In most of the studies, although there is a steep gradient between excess body weight and risk of type $2 \mathrm{DM}$, the largest increases in the risk have been found in the obese range. ${ }^{7,25-27}$ There is strong evidence that obesity is responsible for the global rise in the prevalence of type $2 \mathrm{DM}^{7,8}$ Besides total body fat (reflected by BMI), other factors such as a family history of type 2 DM, body fat distribution, and excess body weight attained either in puberty or in early adult life are also associated with higher risk of type $2 \mathrm{DM}^{7,27,28}$ and may have attenuated the relationship between overweight and type 2 DM in our study.

Multivariate analysis demonstrated that low socioeconomic status defined as a composite of education level and occupation was associated with higher risk of type $2 \mathrm{DM}$ in the present study. There is evidence of a negative association between higher socioeconomic status and prevalence of type $2 \mathrm{DM}^{29-31}$ Data from the UK showed that that both men and women living in deprived areas in a health district had high prevalence of type 2 DM. ${ }^{30}$ Previous studies also found a higher prevalence of the disease among subjects who were less educated, had a lower income or were unemployed.$^{29}$ Furthermore, socioeconomic disadvantage was a significant predictor of type $2 \mathrm{DM}$ incidence in adults over a 34-year period. ${ }^{31}$ Individuals of high socioeconomic status adopt a healthier lifestyle behavior and have fewer risk factors for cardiovascular disease, most of which also influence diabetes. ${ }^{32}$ By contrast, people of lower socioeconomic class are more likely to have reduced access to healthcare services and information and to be obese, physically inactive, and smokers, while less likely to adhere to a healthy diet, all factors associated with the development of type 2 DM. ${ }^{33,34}$ Notably, this association was independent of the effects of age, obesity, and smoking.

We also found that manual workers had increased odds for type $2 \mathrm{DM}$ in univariate analysis. However, multivariate analysis eliminated this association, suggesting that there is an interaction between occupation and other factors. Manual workers are more likely to be less educated, to have a lower income, and to belong to a lower socioeconomic status. Indeed, multivariate analysis showed that a low socioeconomic status was associated with significantly increased odds for type $2 \mathrm{DM}$.

Concerning the association between smoking habits and risk of type $2 \mathrm{DM}$, we showed that the prevalence of the disease was higher in ex-smokers 
than in non-smokers and current smokers. Indeed multivariate analysis demonstrated that previous smoking was associated with higher risk, while current smoking was linked to lower risk of type $2 \mathrm{DM}$. Cross-sectional data from Greece ${ }^{20}$ and prospective studies from other countries demonstrated that the risk of type $2 \mathrm{DM}$ increases in smokers of both genders irrespective of the obesity status, ${ }^{35-38}$ and there is evidence of benefit from smoking cessation on risk of type $2 \mathrm{DM}^{38}$ consistent with the evidence linking smoking with insulin resistance, low-grade inflammation, and increased oxidative stress, factors associated with development of type $2 \mathrm{DM} .^{38,39}$ The low prevalence of current smokers among subjects with type $2 \mathrm{DM}$ found in the present study is probably related to smoking cessation after medical advice when $\mathrm{DM}$ is diagnosed, ${ }^{40}$ a consideration which curtails the power of our study to provide robust conclusions on the association between smoking currently and risk of type 2 DM. In addition, the negative association between smoking and risk for type $2 \mathrm{DM}$ may be related to smoking with genes interaction..$^{41}$ Recent data showed that there are genetic variants in the nicotinic acetylcholine receptors gene which showed a strong association with insulin resistance and type $2 \mathrm{DM}$; these variants were independent of cigarette smoking per se. ${ }^{41}$

We found in univariate analysis that the prevalence of type $2 \mathrm{DM}$ was higher when the number of subjects living together was one or two in comparison with more than two. A plausible explanation for this finding is that older people, who are more likely to have type $2 \mathrm{DM}$, usually live in houses in pairs or alone contrary to the younger participants who have families with children and are less likely to have type 2 DM. In addition, we found in univariate analysis that people living in rural areas had higher prevalence of type $2 \mathrm{DM}(42 \%)$ than those living in urban areas (27.1\%), although it is well established that people living in rural areas, in comparison with those 1 iving in urban areas, are more physically active. The higher prevalence of type $2 \mathrm{DM}$ in people living in rural areas is due to the fact that older people live in rural areas of Greece, who are more likely to have type $2 \mathrm{DM}$. Indeed, in our study there were significantly more dwellers in rural areas in the age groups $>60$ years and the mean age of the rural population was higher than that of urban or suburban dwellers.

We did not find any significant relationship between alcohol consumption and type 2 DM. In our study, a few participants reported heavy alcohol consumption and this has probably resulted in positive association between heavy alcohol consumption and T2DM, as described previously. ${ }^{42}$ Additionally, we did not find a negative relationship between modest or moderate alcohol consumption and prevalence of type 2 DM. Cross-sectional data relating alcohol consumption to the risk of type $2 \mathrm{DM}$ are equivocal. ${ }^{43,44}$ However, there is evidence from prospective studies that modest to moderate alcohol consumption may reduce the risk of diabetes and some studies suggest a U-shaped relationship between alcohol and risk of type $2 \mathrm{DM}^{44,45}$

We did not find differences in the prevalence of type $2 \mathrm{DM}$ between the southern, central, and northern geographic regions of Greece. Univariate analysis showed that the prevalence of the disease was higher in the rural in comparison with the suburban and urban areas of Greece. A possible explanation for this association is that in the age groups $\geq 60$ years, an age-group with high prevalence of type $2 \mathrm{DM}$, there were more people in the rural than in the urban and suburban areas. We also showed that dwellers in the rural areas were on average almost five years older than dwellers in urban or suburban areas. Indeed, multivariate analysis, after adjustment for the effect of age, eliminated the relationship between place of residence and risk of T2DM.

In conclusion, this study showed that in large and representative samples of rural, urban, and suburban adult Greeks, type 2 DM was associated with advancing age, obesity, exposure to smoke, and low socioeconomic status. Data from our country and other countries has shown that the prevalence of the disease is increasing. The results of the present study suggest that the adoption and application of effective public health strategies aiming at prevention of obesity and avoidance of smoking may help to prevent type $2 \mathrm{DM}$.

\section{REFERENCES}

1. King H, Aubert RE, Herman WH, 1998 Global burden 
of diabetes, 1995-2025: prevalence, numerical estimates, and projections. Diabetes Care 21: 1414-1431.

2. Harris MI, Flegal KM, Cowie CC, et al, 1998 Prevalence of diabetes, impaired fasting glucose, and impaired glucose tolerance in U.S. adults. The Third National Health and Nutrition Examination Survey, 1988-1994. Diabetes Care 21: 518-524.

3. Hogan P, Dall T, Nikolov P; American Diabetes Association. Economic costs of diabetes in the US in 2002, 2003 Diabetes Care 26: 917-932.

4. Zimmet P, Alberti KG, Shaw J, 2001 Global and societal implications of the diabetes epidemic. Nature 414: 782-787.

5. World Health Organization. Obesity, 1998. Preventing and Managing the Global Epidemic. Geneva: World Health Organization.

6. Ogden CL, Carroll MD, Curtin LR, McDowell MA, Tabak CJ, Flegal KM, 2006 Prevalence of overweight and obesity in the United States, 1999-2004. JAMA 295: 1549-1555.

7. Colditz GA, Willett WC, Rotnitzky A, Manson JE, 1995 Weight gain as a risk factor for clinical diabetes mellitus in women. Ann Intern Med 122:481-486.

8. Chan JM, Rimm EB, Colditz GA, Stampfer MJ, Willett WC, 1994 Obesity, fat distribution, and weight gain as risk factors for clinical diabetes in men. Diabetes Care 17: 961-969.

9. Andrianakos A, Trontzas P, Christoyannis F, et al, 2003 Prevalence of rheumatic diseases in Greece: a crosssectional population based epidemiological study. The ESORDIG Study. J Rheumatol 30: 1589-1601.

10. Andrianakos AA, Miyakis S, Trontzas $P$, et al, 2005 The burden of the rheumatic diseases in the general adult population of Greece: the ESORDIG study. Rheumatology (Oxford) 44: 932-938.

11. Andrianakos A, Trontzas P, Christoyannis F, et al, 2006 Prevalence and management of rheumatoid arthritis in the general population of Greece-the ESORDIG study. Rheumatology (Oxford) 45: 1549-1554.

12. Andrianakos AA, Kontelis LK, Karamitsos DG, et al, 2006 Prevalence of symptomatic knee, hand, and hip osteoarthritis in Greece. The ESORDIG study. J Rheumatol 33: 2507-2513.

13. République Hellénique. Office National de Statistique de Grèce. Population de fait de la Grèce au recensement du 17 mars 1991. Par départements, éparchies, communesdèmes, communes et localités [Real population of Greece based on the census of March 17, 1991 by departments, provinces, municipalities and communities]. Athènes: République Hellénique; 1994. A:60 Population.

14. Report of the Expert Committee on the Diagnosis and Classification of Diabetes Mellitus, 1997 Diabetes Care 20: 1183-1197.

15. Tentolouris N, Andrianakos A, Karanikolas G, et al, 2009 Prevalence of diabetes mellitus and obesity in the general adult population of Greece: a door-to-door epidemiological study. Diabet Med 26: 451-452.

16. Katsilambros N, Aliferis K, Darviri C, et al, 1993 Evidence for an increase in the prevalence of known diabetes in a sample of an urban population in Greece. Diabet Med 10: 87-90.

17. Lionis C, Bathianaki M, Antonakis N, Papavasiliou S, Philalithis A 2001 A high prevalence of diabetes mellitus in a municipality of rural Crete, Greece. Diabet Med 18: 768-769.

18. Gikas A, Sotiropoulos A, Panagiotakos D, Peppas T, Skliros E, Pappas S 2004 Prevalence, and associated risk factors of self-reported diabetes mellitus in a sample of adult urban population in Greece: MEDICAL Exit Poll Research in Salamis (MEDICAL EXPRESS 2002). BMC Public Health 14; 4:2.

19. Melidonis AM, Tournis SM, Kompoti MK, et al, 2006 Increased prevalence of diabetes mellitus in a rural Greek population. Rural Remote Health 6: 534.

20. Panagiotakos DB, Pitsavos C, Chrysohoou C, Stefanadis C, 2005 The epidemiology of Type 2 diabetes mellitus in Greek adults: the ATTICA study. Diabet Med 22:1581-1588.

21. Panagiotakos DB, Pitsavos C, Skoumas Y, Lentzas Y, Stefanadis C, 2008 Five-year incidence of type 2 diabetes mellitus among cardiovascular disease-free Greek adults: Findings from the ATTICA study. Vasc Health Risk Manag 4: 691-698.

22. Rockwood K, Awalt E, MacKnight C, Mc Dowell I, 2000 Incidence and outcomes of diabetes mellitus in elderly people: report from the Canadian Study of Health and Aging. Can Med Assoc J 162:769-772.

23. Loizou T, Pouloukas S, Tountas C, Thanopoulou A, Karamanos V, 2006 An epidemiologic study on the prevalence of diabetes, glucose intolerance, and metabolic syndrome in the adult population of the Republic of Cyprus. Diabetes Care 29: 1714-1715.

24. Ong KL, Cheung BM, Wong LY, Wat NM, Tan KC, Lam KS, 2008 Prevalence, treatment, and control of diagnosed diabetes in the U.S. National Health and Nutrition Examination Survey 1999-2004. Ann Epidemiol 18: 222-229.

25. Vanderpump MP, Tunbridge WM, French JM, et al, 1996 The incidence of diabetes mellitus in an English community: a 20-year follow-up of the Whickham Survey. Diabet Med 13:741-747.

26. Resnick HE, Harris MI, Brock DB, Harris TB, 2000 American Diabetes Association diabetes diagnostic criteria, advancing age, and cardiovascular disease risk profiles: results from the Third National Health and Nutrition Examination Survey. Diabetes Care 23: 176-180.

27. Must A, Spadano J, Coakley EH, Field AE, Colditz G, Dietz WH, 1999 The disease burden associated with overweight and obesity. JAMA 282: 1523-1529.

28. Wang Y, Rimm EB, Stampfer MJ, Willett WC, Hu FB, 2005 Comparison of abdominal adiposity and overall obesity in predicting risk of type 2 diabetes among men. 
Am J Clin Nutr 81: 555-563.

29. Brown AF, Ettner SL, Piette J, et al, 2004 Socioeconomic position and health among persons with diabetes mellitus: a conceptual framework and review of the literature. Epidemiol Rev 26: 63-77.

30. Connolly V, Unwin N, Sherriff P, Bilous R, Kelly W, 2000 Diabetes prevalence and socioeconomic status: a population based study showing increased prevalence of type 2 diabetes mellitus in deprived areas. J Epidemiol Community Health 54: 173-177.

31. Maty SC, Everson-Rose SA, Haan MN, Raghunathan TE, Kaplan GA, 2005 Education, income, occupation, and the 34-year incidence (1965-99) of Type 2 diabetes in the Alameda County Study. Int J Epidemiol 34: 1274-1281.

32. Tang M, Chen Y, Krewski D, 2003 Gender-related differences in the association between socioeconomic status and self-reported diabetes. Int J Epidemiol 32: 381-385.

33. Millar WJ, Wigle DT, 1986 Socioeconomic disparities in risk factors for cardiovascular disease. Can Med Assoc J 134: 127-132.

34. van der Meer JB, Mackenbach JP, 1999 The care and course of diabetes: difference according to level of education. Health Policy 46: 127-141.

35. Ford ES, Malarcher AM, Herman WH, Aubert RE, 1994 Diabetes mellitus and cigarette smoking. Findings from the 1989 National Health Interview Survey. Diabetes Care 17: 688-692.

36. Feskens EJ, Kromhout D, 1989 Cardiovascular risk factors and the 25-year incidence of diabetes mellitus in middle-aged men. The Zutphen Study. Am J Epidemiol 130: 1101-1108.
37. Rimm EB, Manson JE, Stampfer MJ, et al, 1993 Cigarette smoking and the risk of diabetes in women. Am J Public Health 83: 211-214.

38. Will JC, Galuska DA, Ford ES, Mokdad A, Calle EE, 2001 Cigarette smoking and diabetes mellitus: evidence of a positive association from a large prospective cohort study. Int J Epidemiol 30: 540-546.

39. Facchini FS, Hollenbeck CB, Jeppesen J, Chen YD, Reaven GM, 1992 Insulin resistance and cigarette smoking. Lancet 339: 1128-1130.

40. Stead LF, Bergson G, Lancaster T, 2008 Physician advice for smoking cessation. Cochrane Database Syst Rev 2: CD000165.

41. Yang J, Zhu Y, Cole SA, et al, 2012 A gene-family analysis of 61 genetic variants in the nicotinic acetylcholine receptor genes for insulin resistance and type 2 diabetes in American Indians. Diabetes 61: 1888-1894.

42. Wei M, Gibbons LW, Mitchell TL, Kampert JB, Blair SN, 2000 Alcohol intake and incidence of type 2 diabetes in men. Diabetes Care 23: 18-22.

43. Bazzano LA, Serdula M, Liu S, 2005. Prevention of type 2 diabetes by diet and lifestyle modification. J Am Coll Nutr 24: 310-319.

44. Howard AA, Arnsten JH, Gourevitch MN, 2004 Effect of alcohol consumption on diabetes mellitus: a systematic review. Ann Intern Med 140: 211-219.

45. Perry IJ, Wannamethee SG, Walker MK, Thomson AG, Whincup PH, Shaper AG, 1995 Prospective study of risk factors for development of non-insulin dependent diabetes in middle aged British men. Br Med J 310: 560-564. 